\title{
Technoeconomic and Policy Analysis for Corn Stover Biofuels
}

\author{
Ryan Petter and Wallace E. Tyner \\ Department of Agricultural Economics, Purdue University, 403 West State Street, West Lafayette, IN 47907-2056, USA \\ Correspondence should be addressed to Wallace E. Tyner; wtyner@purdue.edu
}

Received 31 October 2013; Accepted 12 December 2013; Published 4 February 2014

Academic Editors: J.-L. Hu, S. Managi, and J. Zarnikau

Copyright ( 2014 R. Petter and W. E. Tyner. This is an open access article distributed under the Creative Commons Attribution License, which permits unrestricted use, distribution, and reproduction in any medium, provided the original work is properly cited.

Conventional fossil fuels dominate the marketplace, and their prices are a direct competitor for drop-in biofuels. This paper examines the impact of fuel selling price uncertainty on investment risk in a fast pyrolysis derived biofuel production facility. Production cost specifications are gathered from previous research. Monte Carlo analysis is employed with uncertainty in fuel selling price, biomass cost, bio-oil yield, and hydrogen price parameters. Experiments reveal that fuel price has a large impact on investment risk. A reverse auction would shift risk from the private sector to the public sector and is shown to be more effective at encouraging private investment than capital subsidies for the same expected public cost.

\section{Introduction}

This study is a technoeconomic analysis of the fast pyrolysis process. The main objective is to evaluate the effect of fuel price and technical uncertainty on the economic feasibility of biofuels created by catalytic fast pyrolysis using a circulating fluidized bed reactor. Previous studies have focused on creating reliable estimates of the initial capital and operating costs of a biorefinery. This study analyzes the effect of uncertainty in capital cost, hydrogen price, bio-oil yield, feedstock cost, and final product selling price on the appeal of project investment to a private investor. It directly evaluates the effect of two policy instruments-a reverse auction, which effectively fixes the price of the biofuel over the life of the project, and a capital subsidy. This research provides policy makers with information on how these policies could affect biofuel investment decisions.

Supply of advanced biofuels is expected to be a growing part of future liquid supply. US government investment in renewable power and fuels was $\$ 36$ billion in 2012 [1]. Total US investment in the clean energy sector was $\$ 268$ billion in 2012, a 500\% increase since 2004 [2]. Imported petroleum products as a percentage of US petroleum consumption have decreased from $60 \%$ to $40 \%$ between 2005 and 2012 [3]. Supply of advanced biofuels is expected to be a growing part of future liquid supply $[4,5]$. Research and development of economically attractive alternative fuel sources are ongoing in many nations around the world.

Catalytic fast pyrolysis is a process used to convert biomass to a bio-oil. This process is chosen for this study because of the relatively low cost per gallon [6-9]. Pyrolysis oil can be refined to diesel, gasoline, or jet fuel. Detailed descriptions of the fast pyrolysis process are available in the previous literature [9-15]. In this study, we use corn stover (corn residue), but the process can handle most cellulosic feedstocks. The remaining char and off-gas are burned in the production of electricity. Excess electricity can be sold [6].

A review of literature found no strong naming convention for pyrolysis derived biofuels. Cellulosic biofuels, biomass derived liquids, hydrocarbon fuels, and "drop-in" fuels all refer to renewable fuel derived from biomass. We use the term "biofuels" to describe biofuels produced via fast pyrolysis, although it can have many different meanings.

Technoeconomic analysis of fast pyrolysis is a method of forecasting the potential returns to an investment in a fast-pyrolysis production facility. It has been used extensively for studying feasibility of biofuel production. The National Renewable Energy Laboratory and the Pacific Northwest National Laboratory have conducted a series of technoeconomic analyses on a range of advanced biofuels and production methods $[6,8,14]$. This research produced detailed projections of the total cost of large capital investments, 
although there is some variability in the results [15]. The result of technoeconomic analysis is a cost break-even selling fuel price at which the future sales of transportation liquids and byproducts are equal to the present value of capital and operating expenditures, that is, a minimum fuel selling price. Research has shown that pyrolysis derived biofuels could be produced competitively, with estimated fuel selling prices ranging from $\$ 2.00$ to $\$ 2.71$ per gallon ( $\$ 0.53$ to $\$ 0.72$ per liter) $[8,9,16]$. These studies suggest that commercial production of biofuel via fast pyrolysis is a competitive method of increasing domestic supply of transportation fuels.

According to research by Brown and Brown (2013), 215 million gallons per year (814 million liters per year) of cellulosic biofuel facilities are expected to be produced in the US by 2014 [15]. KiOR, ClearFuels, and Sundrop Fuels are three of the nine companies with commercial-scale projects expected to begin production by 2014 [15]. Meier et al. (2013) summarized current research, interest, and production of biofuels from pyrolysis in the six member countries of the IEA Bioenergy Task 34 [17]. They highlight Envergent and KiOR as commercial interests in the United States.

Although this study focuses on the economics of biofuel production, there are environmental effects as well [1822]. The impact of biofuel expansion on greenhouse gas emissions is debated. Snowden-Swan and Male found that GHG reduction estimates from the petroleum baseline range from 62 to $68 \%$ [23]. However, if dedicated energy crops are used as feedstock, increased demand for land might cause an overall increase in greenhouse gas emissions [24]. It is generally agreed that the corn stover to biofuels pathway has no land use change impacts. There are other societal and economic effects from constructing and managing large production facilities and from harvesting, storing, processing, and transporting large amounts of biomass.

This research focuses on the effect of reverse auctions on the variance of net present value and internal rate of return. The government has many options for affecting biofuel prices, but these are not discussed here because they are covered in the previous literature $[25,26]$. In a reverse auction, biofuel suppliers bid against each other for the opportunity to supply a certain volume of biofuel [27]. The result is a long-term forward contract with a competitive known price. The winning (lowest) bidder would have the biofuel price fixed for the duration of the contract, which is here assumed to be 20 years. The government would decrease long-term risk and obtain a competitive long-term price. In addition to examining the risk reduction impacts of the reverse auction, we also compare it to a capital subsidy with the same expected cost to government as a reverse auction.

\section{Methodology}

The method of production of biofuel used in this study is based on a technoeconomic analysis done at Iowa State University [6]. That study analyzed the production of biofuel via catalytic fast pyrolysis and hydroprocessing, a similar process to the commercial implementation by KiOR [28]. This study uses the same assumptions to validate the base case
TABLE 1: Economic assumptions.

\begin{tabular}{lccc}
\hline Parameter & Input value & Units & Source \\
\hline Real discount rate & $10 \%$ & $\%$ & {$[6]$} \\
Nominal interest rate & $7.5 \%$ & $\%$ & {$[6]$} \\
10 year depreciation & $200 \%$ & $\%$ & {$[14]$} \\
Plant depreciable life & 7 & yrs & {$[14]$} \\
Equity & $50 \%$ & $\%$ & {$[6]$} \\
Financing & $50 \%$ & $\%$ & {$[6]$} \\
Loan term & 10 & yrs & {$[6]$} \\
Construction time & 3 & yrs & {$[14]$} \\
\% spent in year 1 & $8 \%$ & $\%$ & {$[14]$} \\
\% spent in year 2 & $60 \%$ & $\%$ & {$[14]$} \\
$\%$ spent in year 3 & $32 \%$ & $\%$ & {$[14]$} \\
Income taxes & $35 \%$ & $\%$ & {$[14]$} \\
\hline
\end{tabular}

but then uses financial and economic assumptions that more closely represent reality in the marketplace. Additionally, this report adds uncertainty distributions to some parameters.

In this section, we first recreate the analysis done by Tristan Brown et al. [6]. We then detail the data used in our analysis and show how it differs from Tristan Brown et al. Next, we describe how uncertainty is modeled. Finally, we describe the eight experimental cases examined in this study.

Much of the research on fast pyrolysis has been done by chemists and engineers. In order to recreate the analysis done, we initially used the same spreadsheet model as some chemical engineers: a discounted cash flow rate of return analysis [14, 29]. Many economists employ a different treatment of inflation, debt repayment, taxes, and other factors. Of course, not all engineers use only the discounted case flow rate of return method, nor have all economists used the more complete economic and financial analysis. However, for simplicity in presentation, we will differentiate the two types of spreadsheets by labeling them as engineering analysis and economic analysis, respectively.

2.1. Engineering Analysis. To be certain that our spreadsheet was an accurate representation of the original Brown data, we first recreated the analysis by Tristan Brown et al. [6] using an engineering analysis. Some of the data needed to recreate the analysis was not available in that paper. For those parameters we assumed that they match those in a previous Iowa State University study [14].

The economic assumptions used by Wright et al. [14] or Tristan Brown et al. [6] are documented in Table 1.

Some of the key economic assumptions are a total project timeline of 23 years, $50 \%$ debt financing, a 10\% discount rate, a loan payback period of 10 years, a tax rate of $35 \%$ of net income, and a construction time of 3 years. No inflation rate was specified in either analysis.

In addition to the economic variables, we used many of the technical variable values as Tristan Brown et al. [6]. The technical assumptions we used in our recreation are summarized in Table 2. More details, including the number and type of employees and other assumptions are available from the authors on request. 
TABLE 2: Technical assumptions.

\begin{tabular}{|c|c|c|c|}
\hline Parameter & Input value & Units & Source \\
\hline Working capital & $15 \%$ & $\%$ & {$[6]$} \\
\hline Project contingency & $\$ 61,490,157$ & $\$$ & Calculated from data in [14] \\
\hline Working capital expenditure & $\$ 55,341,142$ & $\$$ & Calculated from data in [14] \\
\hline Total capital investment & $\$ 429,000,000$ & $\$$ & {$[6]$} \\
\hline Land & $\$ 4,717,915$ & $\$$ & Calculated from data in [14] \\
\hline Nominal fixed capital Investment & $\$ 394,799,061$ & $\$$ & Calculated from data in [14] \\
\hline Plant operation/online time & 329.5 & days/yr & Calculated from data in [6] \\
\hline Startup production rate & $75 \%$ & $\%$ & [14] \\
\hline Startup variable expense & $87.5 \%$ & $\%$ & [14] \\
\hline Input capacity & 2,000 & MT/day & {$[6]$} \\
\hline Annual feedstock use & 659,000 & $\mathrm{MT} / \mathrm{yr}$ & {$[6]$} \\
\hline Bio-oil yield & $63.00 \%$ & $\mathrm{Mg} / \mathrm{Mg}$ & {$[6]$} \\
\hline Gas conversion rate & $21.0 \%$ & $\mathrm{Mg} / \mathrm{Mg}$ bio-oil & [14] \\
\hline Diesel conversion rate & $21.0 \%$ & $\mathrm{Mg} / \mathrm{Mg}$ bio-oil & {$[14]$} \\
\hline Feedstock cost & 83 & $\$ / \mathrm{MT}$ & {$[6]$} \\
\hline Catalyst replacement costs & $1,767,000$ & $\$ / y r$ & [14] \\
\hline Electricity produced & $223,000,000$ & $\mathrm{kwh} / \mathrm{yr}$ & {$[6]$} \\
\hline Electricity use & 11,490 & kw/hour & {$[14]$} \\
\hline Electricity price & $\$ 0.0540$ & $\$ / \mathrm{kwh}$ & {$[14]$} \\
\hline Hydrogen use & 2,041 & $\mathrm{~kg} /$ hour & [14] \\
\hline Hydrogen price & $\$ 1.33$ & $\$ / \mathrm{kg}$ & {$[6]$} \\
\hline
\end{tabular}

Besides technical parameters, financing assumptions also affect the analysis. Tristan Brown et al. [6] do not provide details, but we assume that their engineering spreadsheet is similar to work done by Humbird et al. [29]. Humbird et al. [29] assume that land is paid immediately with equity, interest is paid off during the first three construction years, and that tax benefits from losses on operations are claimed in the current year. Finally, Humbird et al. [29] do not include loan or interest payments when computing tax payments.

Using the engineering analysis and the above data, we found a facility fuel output of 58.6 millions of gallons per year (222 millions of liters). Wright et al. [14] reported a fuel yield of 58.2 MGY, and 57.4 MGY was reported by Tristan Brown et al. [6]. We found a minimum fuel selling price of $\$ 2.55$ per gallon ( $\$ 0.67$ per liter) compared to $\$ 2.57$ ( $\$ 0.68$ per liter) in Tristan Brown et al. [6]. Thus, we can be confident that we have accurately reconstructed the Tristan Brown et al. [6] assumptions and results.

The fuel price was determined using the goal seek add-in from Excel to set net present value equal to zero. Minimum fuel selling price is the price that makes the net present value with a $10 \%$ real discount rate equal to zero. The $10 \%$ discount rate is sometimes called a hurdle rate. We do not know what discount rate a private investor would require. However, choosing a different discount rate would not change the conclusions from this study. The conclusions from this study are based on variability not break-even fuel price. We have chosen to use the $10 \%$ real discount rate used in Tristan Brown et al. [6]. Thus, the term "minimum fuel selling price" is analogous to "break-even price."
2.2. Economic Spreadsheet Analysis. We did our economic analysis in an Excel spreadsheet using most of the same technical data values from Tristan Brown et al. [6]. This section provides details on changes made to the technical and economic parameters. First, we describe financing differences. Then, we describe the difference in assumed tax rate. Finally, we examine changes in parameter values and their effect on expected return.

In the previous section we described financing assumptions present in the engineering analysis. These were obtained from a report by Humbird et al. [29] and seem to be used in Table D-3 in Wright et al. [14]. We assume that they are also used in Tristan Brown et al. [6]. We chose different financing assumptions in our economic analysis which have material effects on the return on investment. For example, the engineering spreadsheets assumed the inflation rate to be zero. However, average inflation as shown in the US consumer price index has been $2.9 \%$ over the past 30 years (Bureau of Labor Statistics 2013a). We assumed a 2.5\% inflation rate. The differences in financing assumptions are summarized in Table 3. Depreciation for tax purposes was the same in both the engineering and economic analyses.

The combined effect on investment return of the assumption differences was calculated to see the importance of the approach. As described previously, our recreation of the previous studies' assumptions found a $10.0 \%$ internal rate of return at a fuel price of $\$ 2.55$ per gallon ( $\$ 0.67$ per liter). With our financing assumptions but not our price or tax assumptions, a fuel price of $\$ 2.55$ per gallon $(\$ 0.67$ per liter) results in a $12.0 \%$ return. Using the economic financing assumptions, we find a break-even fuel price of $\$ 2.40$ per 
TABLE 3: Differences in financing assumptions.

\begin{tabular}{lc}
\hline Engineering analysis & Economic analysis \\
\hline Land paid with equity & $\begin{array}{c}\text { Land included in capital } \\
\text { investment and cost is divided } \\
\text { between financing and equity } \\
\text { Tax benefits or losses occur in } \\
\text { the year they occur }\end{array}$ \\
$\begin{array}{lc}\text { Tnterest is paid with equity } \\
\text { during construction }\end{array}$ & $\begin{array}{c}\text { Interest is compounded annually } \\
\text { during construction (interest is } \\
\text { Loan and interest are not } \\
\text { included in computing taxes } \\
\text { Inflation is assumed to be zero }\end{array}$ \\
\hline
\end{tabular}

gallon ( $\$ 0.63$ per liter). In other words, there is a $6.3 \%$ difference in the break-even price between the economic and engineering analyses and a $2.0 \%$ difference in the internal rate of return.

In addition to these financing assumption differences, three technical parameter values were changed: hydrogen price, feedstock price, and fuel yield. These variables have min, mode, and max values, which make up the Pert distribution input parameters for the stochastic analysis. Details on the changes to hydrogen price, feedstock price and fuel yield are explained in Section 2.3. However, for reference these changes are summarized in Table 4.

Hydrogen price, feedstock price, and fuel yield each have new mean values. Hydrogen has a much higher price, and fuel yield is slightly lower. The combined effect shifts the breakeven fuel price from $\$ 2.40$ to $\$ 2.65$ per gallon ( $\$ 0.63$ to $\$ 0.70$ per liter). Remember that our recreation of Tristan Brown et al. [6] had a break-even price of $\$ 2.55$ per gallon ( $\$ 0.67$ per liter).

Besides the adjustments made to variables in Table 4, income tax was adjusted lower. The tax rate in Tristan Brown et al. [6] is $35 \%$, which is the statutory corporate federal tax rate. Effective tax rates measure the proportion of taxes paid to economic income. For profitable firms filing a Schedule M3 , the effective federal tax rate was about $13 \%$ in 2010 [32]. Including foreign, state, and local taxes for all firms filing a Schedule M-3 raises the effective tax rate to about 23\% [32]. Therefore, for this study, we assume a tax rate of $24 \%$ because it is closer to the tax rate paid by corporations.

The lower tax rate has a less severe effect than the previous changes. Lowering the tax rate from $35 \%$ to $24 \%$ in our recreation of the Tristan Brown et al. [6] study lowers the break-even price from $\$ 2.65$ to $\$ 2.62$ per gallon $(\$ 0.70$ to $\$ 0.69$ per liter). Table 5 summarizes the changes made and their effect on break-even price.

2.3. Technical Uncertainty. The uncertainty inherent in a biofuel production facility stems from a multitude of sources, but four are chosen because of their importance to project viability. The four parameters modeled as uncertain are grouped into technical uncertainty and fuel price uncertainty. The parameters labeled with technical uncertainty are the price of the feedstock, the bio-oil yield, and hydrogen purchase price. Table 6 shows the share in total cost of capital investment, feedstock, hydrogen, and other operating cost. Bio-oil yield clearly could have an important impact on economic viability, as the higher the yield, the lower the unit cost. Later, in one of the simulation cases, we will test the importance of the capital cost assumption.

In related studies, researchers conduct uncertainty analysis by showing the impact of changing certain variables one at a time and determining the maximum and minimum rate of return or fuel selling price $[6,14]$. These analyses do not provide probability of the high or low values or the assessment of combined uncertainty. These studies use sensitivity analysis to identify the variables that are most critical to the cash flow. However, sensitivity analysis does not consider variable interaction, so it provides a less quantifiable measure of risk. These studies determine that two of the most important variables in terms of their expected effect on the break-even price are bio-oil and fuel yield and biomass cost. Other important parameters reported are electricity selling price, interest rate, and project investment cost.

This study uses Monte Carlo simulation, which uses input distributions rather than fixed values. The Palisades risk and decision analysis software, @Risk, is used to account for variability in the technical parameters: biomass cost, bio-oil yield, and hydrogen price. Monte Carlo simulation creates input distributions based on data from the literature, econometric estimates, or other sources. Common distributions that are used for input costs are the Triangular and Pert. Both of these distributions have as parameters the max, mode, and min values. Experts can more easily answer expected, maximum, and minimum parameter values than selecting a mean and standard deviation as for a normal distribution. The main difference between the two is that the Pert has more of the probability density closer to the mean, and the triangular has more towards the max and min values. Since Pert has more probability near the mean, it was chosen for this study.

The high, mode, and low values for bio-oil yield are the same as used by previous studies $[6,14]$. Bio-oil yield varies depending on factors such as the type of catalyst and the rate of temperature change during the pyrolysis reaction. Yields are expressed as weight of oil as a percentage of the weight of starting biomass. Bio-oil yields of $70 \%, 63 \%$, and $49 \%$ set out the max, mode, and min for a Pert distribution. The mean value for this Pert distribution, as reported earlier, is $61.8 \%$. This changes the annual biofuel production from 58.6 MGY to $57.5 \mathrm{MGY}$, nearly the same as the $57.4 \mathrm{MGY}$ reported in Tristan Brown et al. [6].

The feedstock price varies depending on material and the cost of preparing the material for pyrolysis. Prices of $\$ 110$, $\$ 83$, and $\$ 55 / \mathrm{MT}$ are reported in the same studies $[6,14]$. We use these prices as the maximum, mode, and minimum for a Pert distribution. The mean value, as shown in Table 4, is $\$ 82.83 / \mathrm{MT}$.

The other technical parameter modeled with uncertainty is hydrogen price. The National Research Council studied conventional and advanced hydrogen production related to their study of hydrogen fuel cell vehicles [30]. Using the H2A model, they found costs of $\$ 1.60$ and $\$ 1.90$ in 2005 dollars, respectively, for natural gas reforming and coal gasification. 
TABLE 4: Differences in stochastic parameter estimates.

\begin{tabular}{lccccccc}
\hline Parameter & $\begin{array}{l}\text { Old value Tristan } \\
\text { Brown et al. [6] }\end{array}$ & Min & Mode & Max & Mean value & Unit & Source \\
\hline Hydrogen price & 1.33 & 1.33 & 2.02 & 2.94 & 2.06 & $\$ / \mathrm{kg}$ & {$[30,31]$} \\
Feedstock price & 83 & 55 & 83 & 110 & 82.83 & $\$ / \mathrm{MT}$ & {$[6]$} \\
Fuel yield & 63 & 49 & 63 & 70 & 61.8 & $\%$ & {$[6]$} \\
\hline
\end{tabular}

TABLE 5: Alternative measures of break-even price.

\begin{tabular}{lcc}
\hline Description of conditions & \$ per gallon & \$ per liter \\
\hline $\begin{array}{l}\text { As reported in Tristan Brown et al. [6] } \\
\begin{array}{l}\text { Tristan Brown et al. [6] as recreated by } \\
\text { authors with engineering financing }\end{array}\end{array}$ & $\$ 2.57$ & $\$ 0.68$ \\
$\begin{array}{l}\text { assumptions, higher tax rate } \\
\begin{array}{l}\text { Old variable values, economic financing } \\
\text { assumptions, higher tax rate }\end{array}\end{array}$ & $\$ 2.40$ & $\$ 0.67$ \\
$\begin{array}{l}\text { New variable values, economic financing } \\
\text { assumptions, higher tax rate }\end{array}$ & $\$ 2.65$ & $\$ 0.63$ \\
$\begin{array}{l}\text { New variable values, economic financing } \\
\text { assumptions, lower tax rate }\end{array}$ & $\$ 2.62$ & $\$ 0.69$ \\
\hline
\end{tabular}

TABLE 6: Cost shares for key cost components.

\begin{tabular}{lcc}
\hline Item & NPV cost $(\$)$ & Cost share (\%) \\
\hline $\begin{array}{l}\text { Capital cost (with working } \\
\text { capital) }\end{array}$ & $\$ 303,129,655$ & $30.3 \%$ \\
Feedstock & $\$ 344,499,049$ & $34.4 \%$ \\
Hydrogen & $\$ 209,663,508$ & $21.0 \%$ \\
Other operating cost & $\$ 142,824,530$ & $14.3 \%$ \\
\hline Total & $\$ 1,000,116,742$ & $100.0 \%$ \\
\hline
\end{tabular}

Source: author's calculations.

Adjusted to 2011 dollars using the Producer Price Index for Industrial Commodities, the natural gas reforming cost increases to $\$ 2.02$ [33]. A 2010 study conducted by Iowa State and Texas A\&M summarized the cost estimates of various studies in the production of hydrogen [31]. They found coal gasification with current technology and carbon sequestration costing between $\$ 1.25$ and $\$ 1.83$ and natural gas steam methane reforming costing between $\$ 2.33$ and $\$ 3.17$, in 2007 dollars. The low estimate for steam methane reforming using natural gas was $\$ 2.33$. Adjusted to 2011 dollars using the Producer Price Index for Industrial Commodities this cost increases to $\$ 2.94$ [33]. We use a low price of $\$ 1.33$, mode price of $\$ 2.02$, and high price of $\$ 2.94$ per kilogram. These three technical parameters were summarized in Table 4.

2.4. Fuel Price Uncertainty. Diesel and gasoline compete with biofuel, so the prices of those fuels directly impact the economic feasibility of biofuel production. The selling price of fuel in this study is assumed to be the same as wholesale gasoline and diesel prices [6]. The DOE projects real increases in the price of crude oil but with wide uncertainty as shown by the differences among the high, reference, and low price scenarios in Figure 1 [4]. Figure 1 displays projections from

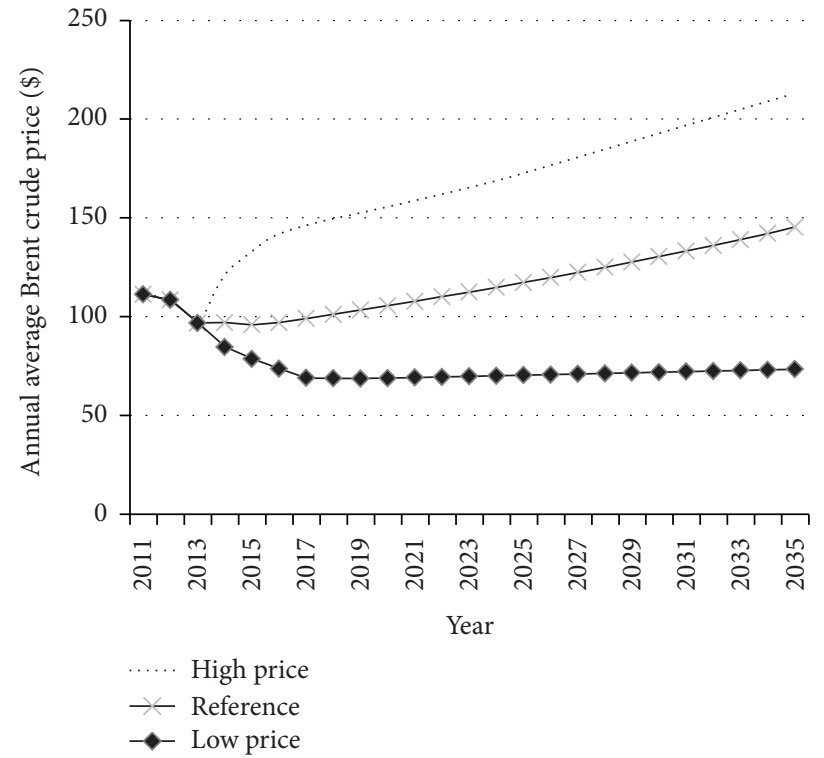

FIGURE 1: Projected Brent crude prices from Annual Energy Outlook 2013 [4].

the 2013 Annual Energy Outlook for Brent crude spot prices from 1990 to 2040 in constant 2011 dollars per barrel.

To capture the uncertainty regarding fuel prices and the impact of selling price uncertainty on the expected return on investment, we employ three fuel price projections: (1) a fixed price, (2) a price that fluctuates but remains at about the same level on average over the time period, and (3) a price that fluctuates but increases at a rate similar to the DOE reference scenario.

In the first price projection, the fuel price is fixed in real terms. In nominal terms the price increases because of the $2.5 \%$ inflation rate. This fixed fuel price represents a reverse auction outcome. If the government created a longterm forward contract based on a reverse auction, from a private perspective the fuel selling price would be fixed.

The nondeterministic steady price is useful for understanding the importance of variability in fuel selling price on the economic profitability of investment in a biofuel refinery. It has about the same average price as the fixed price, but the uncertainty in fuel price is expected to increase the risk of investment.

The nondeterministic price with upward trend was created to be similar to DOE projections from 2013 to 2035. The starting gasoline price in our analysis is the DOE projection for 2013 (2011 dollars) but subtracting $\$ 0.70$ per gallon ( $\$ 0.18$ 
per liter) to convert retail prices to wholesale prices [34]. This is the same starting price used for the fixed price. Our forecast for the uncertain price with upward trend also matches the DOE forecast less $\$ 0.70$ per gallon $(\$ 0.18$ per liter) for expected fuel price in 2035 , which is the final project year.

We tested both mean reversion and Brownian motion with trend models. The Brownian motion with trend model had a lower standard deviation and did not follow the DOE projections as closely. Figure 2 compares the projections: static DOE projections, mean reversion, mean reversion with upward drift, and Brownian motion with upward drift. The three gasoline prices used in the experiments are static price, mean reversion with no upward trend, and mean reversion with upward trend.

Tristan Brown et al. [6] assume that half of the fuel output from the plant is gasoline and half is diesel. These fuels have different selling price, although their prices are highly correlated with each other. Regressing the historic wholesale prices of gasoline and diesel for 2004-2012, we found an $R$-square of $97 \%$. We used the intercept and slope of this regression, which were -0.322 and 1.201 , to find the diesel projected prices based on gas prices. This is shown in the following equation:

$$
\text { Diesel price } t_{t}=-0.322+1.201 * \text { Gasoline price }_{t} \text {. }
$$

The fuel produced in this project is $50 \%$ each of diesel and gasoline. Therefore, we forecast a combined price by using the average of the diesel and gasoline price for each year. The cumulative results are fuel price forecasts for the next 23 years, from 2013 to 2035.

2.5. Experimental Cases. There is a high expected variance in gasoline and diesel prices over the time period. Thus, the experiments are chosen to help identify the effect of government intervention on the investment decision given that price uncertainty. Together, these cases provide an understanding of the impact of fuel price uncertainty on investment in a biofuel production facility.

(1) A base case with a fixed fuel price of $\$ 2.68$ per gallon (\$0.71 per liter) and no uncertain variables.

(2) A stochastic case (for all three technical uncertain variables) plus an uncertain fuel price that has no upward trend.

(3) A stochastic case (for all three technical uncertain variables) plus an uncertain fuel price that has an upward trend keyed to the DOE reference price forecast.

(4) A stochastic case (for all three technical uncertain variables) but with a break-even fuel price. The fuel price is fixed in real terms to provide the same expected net present value as in case two (\$2.68 per gallon or $\$ 0.71$ per liter). This price is a possible outcome of a reverse auction.

(5) A stochastic case (for all three technical uncertain variables) but with a fuel price fixed to provide the

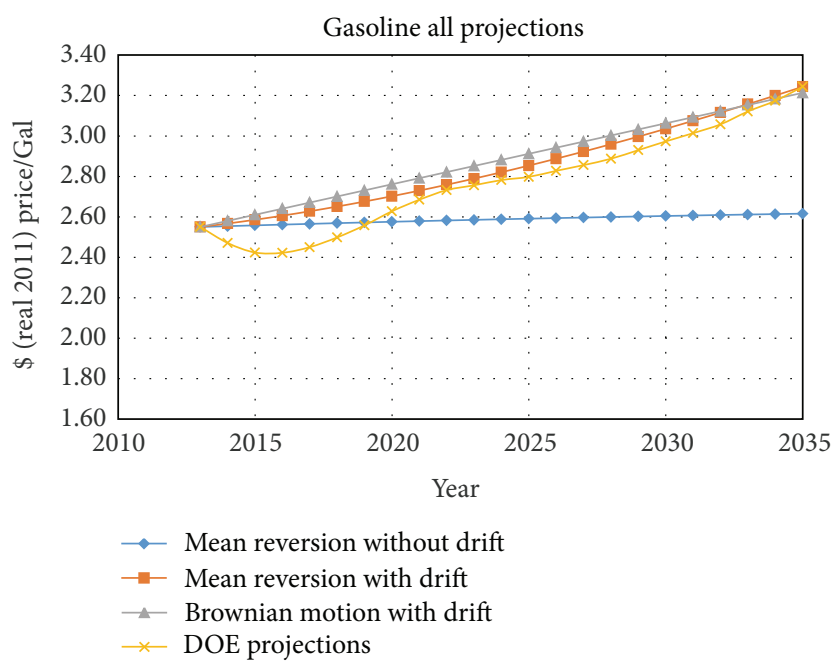

FIGURE 2: Comparison of all gasoline price projections.

same expected economic net present value as in case three ( $\$ 2.92$ per gallon $\$ 0.77$ per liter). This price is also a possible outcome of a reverse auction.

(6) A stochastic case that matches case three but with $20 \%$ higher capital investment cost.

(7) A stochastic case that matches case three but with a fixed fuel selling price ( $\$ 2.92$ per gallon $\$ 0.77$ per liter) for 45 million gallons (170 million liters) of fuel per year (for project years 5-23).

(8) A stochastic case that matches case three but with a $\$ 5$ million capital subsidy. This is designed to compare public intervention in the form of a capital subsidy with a reverse auction. Cases (7) and (8) have the same expected government cost.

\section{Results and Discussion}

This section presents and summarizes the results of the analysis. The next section draws conclusions from these results.

3.1. Base Case. Case 1 , the base case, is a completely deterministic model with the hydrogen price, bio-oil yield, feedstock price, and fuel selling price values fixed at their expected mean levels. It is the only case where the parameters are all deterministic. The values of the technical parameters are fixed at their mean levels which, for the Pert distribution, are calculated as shown in the following equation:

$$
\text { Pert Mean }=\frac{\min +4 * \operatorname{mode}+\max }{6} .
$$

The mean values are shown in Table 7.

Results are shown in net present value (NPV), internal rate of return (IRR), and benefit cost ratio $(B / C)$. Net present value provides a discounted measure of project worth. The project is accepted when NPV is greater than zero. One problem with NPV is the large numbers that can come from 
TABLE 7: Case 1 technical variable values.

\begin{tabular}{lc}
\hline Variable name & Input value \\
\hline Hydrogen price & $\$ 2.06 /$ gal or $\$ 0.71 /$ liter \\
Feedstock price & $\$ 82.83 / \mathrm{MT}$ \\
Fuel yield & $61.8 \%$ \\
\hline
\end{tabular}

TABLE 8: Case 1 results.

\begin{tabular}{lccc}
\hline & NPV & IRR (real) & $B / C$ \\
\hline Economic & $\$ 0.00$ & $10.0 \%$ & 1.00 \\
Financial & $\$ 16,641,078$ & $11.0 \%$ & 1.09 \\
\hline
\end{tabular}

large projects. Another problem is choosing an appropriate discount rate. IRR measures the rate of interest that makes the NPV equal zero. IRR assumes that profits can be reinvested at the IRR, but this may not be possible.

Table 8 summarizes the results from the base case.

Table 8 is separated into a financial analysis and an economic analysis. The economic analysis is before financing and taxes while the financial is after accounting for those. The economic analysis is also known in the financial literature as asset based analysis. There are two competing causes for differences in the financial and economic NPV and IRR. The first is that the nominal loan interest rate $(7.5 \%)$ is lower than the real discount rate (10\%). When the interest rate is lower than the discount rate, as the equity ratio decreases, the return increases. The rational private investor under these conditions would seek as much financing as possible for capital investments when the loan interest rate is below the discount rate. We assumed a 50\% equity structure. Thus, including financing improves the project return.

Second, tax payments are included in financing, which lowers project return. All of the cases with positive expected IRR pay taxes during the project time period. When returns are higher, tax payments are greater. In some cases that follow, when returns are higher, the tax payment cost exceeds the benefit from financing. In those cases, the economic NPV will be higher than financial NPV. In Case 1, however, the benefit from financing exceeds the cost from tax payments.

In the base case, the project has an economic NPV of zero but a positive financial NPV. We chose to use an economic break-even fuel price for this case. At a price of $\$ 2.68$ ( $\$ 0.71$ per liter), the financial IRR is $11.0 \%$ and the economic IRR is $10.0 \%$. The financial break-even price is $\$ 2.62$ ( $\$ 0.69$ per liter). The financial IRR at this price is $10 \%$, and the economic is $9.2 \%$. The economic break-even price is $\$ 2.68$ ( $\$ 0.71$ per liter), higher than the $\$ 2.57$ ( $\$ 0.68$ per liter) break-even price in the Tristan Brown et al. [6] study.

Investors are risk averse, so without knowing the riskiness of an investment one cannot discern its attractiveness. In the next scenario, we examine the impact of uncertainty.

3.2. Stochastic Steady Price Case. In Case 2, we employ Monte Carlo analysis to predict uncertainty in NPV given uncertainty in technical and market parameters. The breakeven fuel selling price in the base case was $\$ 2.68$ per gallon

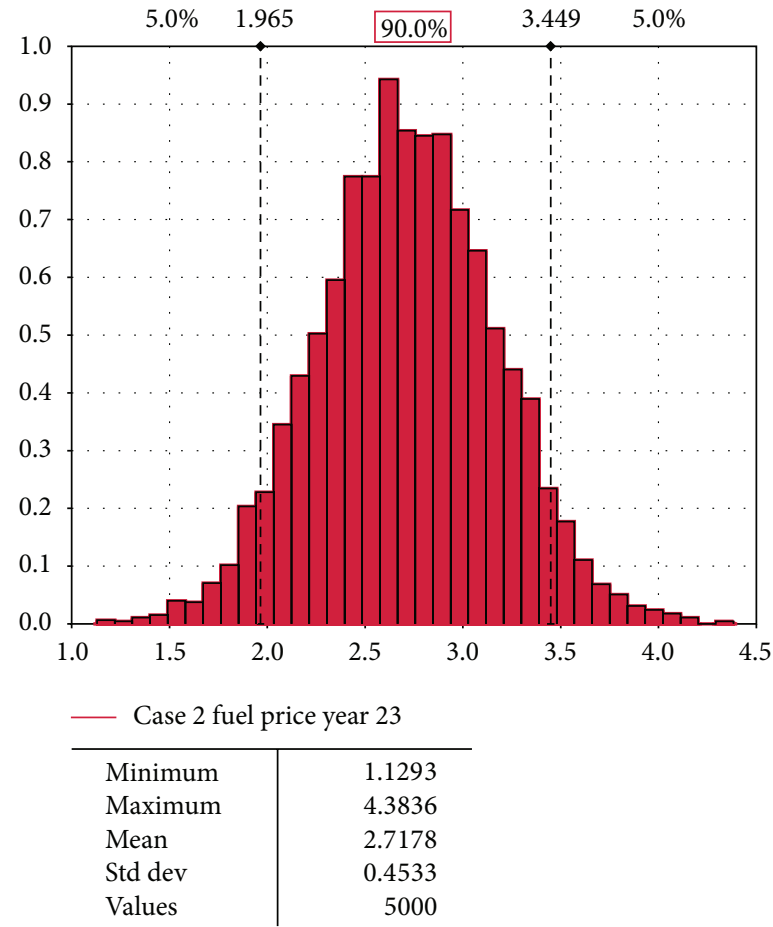

FIGURE 3: steady fuel price distribution.

(\$0.71 per liter). This case has the same economic NPV as in Case 1 but adds uncertainty.

While the previous case could be shown in a small table, the results of Case 2 are better understood using graphs of input and output distributions. As noted earlier, the technical variables are assumed to have Pert probability distributions. The technical parameters for each year are considered to be independent of each other, so the distribution curves are nearly identical for each project year.

The fuel selling price is nondeterministic in a different way because of the mean reversion calculations. The fuel selling price distribution will have variance from year to year because of the mean reverting process. Figure 3 shows the outcome of a fuel price distribution in the final project year. There is an $80 \%$ probability that the ending price was between $\$ 2.34$ and $\$ 3.10$ per gallon ( $\$ 0.62$ and $\$ 0.82$ per liter). The maximum fuel price in year 23 was $\$ 4.38$ ( $\$ 1.16$ per liter) and the minimum was $\$ 1.13$ ( $\$ 0.30$ per liter).

On average, the economic NPV was near zero. However, there was a total range of $\$ 837$ million for the economic case. Table 9 summarizes some of the key results from this experiment.

The financial case had a higher standard deviation for IRR but lower standard deviation for NPV. In calculating the economic IRR, there were 105 errors out of the 5,000 iterations during the simulation. The financial case IRR had 121 errors. Errors occur in the IRR because, under some combination of random draws from the input distributions, the flows are so skewed in the negative or positive direction (usually negative) that no IRR can be found. Under that condition, the IRR function returns an error, and the result is 
TABle 9: Case 2.

\begin{tabular}{|c|c|c|c|c|c|c|}
\hline & \multicolumn{3}{|c|}{ Economic } & \multicolumn{3}{|c|}{ Financial } \\
\hline & NPV & IRR (nominal) & $B / C$ & NPV & IRR (nominal) & $B / C$ \\
\hline Expected value & $\$ 0$ & $10.0 \%$ & 1.00 & $\$ 16,641,078$ & $11.0 \%$ & 1.09 \\
\hline Standard deviation & $\$ 100,993,377$ & $3.9 \%$ & 0.29 & $\$ 76,669,403$ & $4.8 \%$ & 0.40 \\
\hline $\operatorname{Max}$ & $\$ 427,930,098$ & $22.8 \%$ & 2.24 & $\$ 339,121,179$ & $26.9 \%$ & 2.76 \\
\hline Min & $(\$ 408,886,573)$ & $-15.6 \%$ & -0.19 & $(\$ 295,088,669)$ & $-13.6 \%$ & -0.53 \\
\hline Probability of loss & $50.3 \%$ & & & $40.8 \%$ & & \\
\hline
\end{tabular}

reported as such in the Monte Carlo outputs. For example, for the financial case, the mean IRR is based on 4879 iterations instead of 5000. Errors are not found in NPV calculations. For this reason NPV is generally a better measure of risk distributions.

The economic case had a wider NPV distribution than the financial case, and this will remain true for all of the experiments. This is because of the tax payments which reduce gains in highly profitable iterations and reduce losses (due to negative taxes) in low profitability or loss iterations. One standard deviation in the financial case is $\$ 77$ million, while it is $\$ 101$ million in the economic case. These standard deviations are based on the input distributions from the uncertain variables. Since the underlying input distributions will not change in the stochastic cases, the standard deviations should be about the same from case to case except when uncertain variables are held constant. The financial NPV was slightly better than the economic NPV.

The economic NPV ranged from $-\$ 409$ million to $+\$ 428$ million. There was a $50 \%$ chance of a loss for the economic case, as the mean of the distribution was near zero. The financial NPV had an $80 \%$ probability of being between $-\$ 81$ million and $\$ 113$ million. The maximum was $\$ 339$ million and the minimum was $-\$ 295$ million. There was a $41 \%$ probability that the financial NPV was less than zero.

This case enforces the wide variability and high amount of risk inherent in an investment of this magnitude. Even if the expected IRR was $20 \%$ instead of $11 \%$, the wide spread of possible outcomes would make investment risky. Remember, the initial capital investment is \$429 million. In this result there is a spread in the financial NPV of $\$ 634$ million. This experiment only had three technically uncertain variables. Including others would make the spread of possibilities even greater. The next case creates an increasing fuel selling price that more closely matches DOE projected fuel prices.

3.3. Stochastic Increasing Case. Case 3 has an uncertain fuel price that increases to, on average, meet DOE projections in 2035. It is the same as in the second case, except that it has a rising fuel selling price. The ending price is higher in Case 3 , increasing to $\$ 3.41$ per gallon ( $\$ 0.90$ per liter) of fuel on average in 2011 real dollars. One standard deviation is $\$ 0.40$ (\$0.11 per liter). Table 10 summarizes the results from this scenario.

The increasing fuel price had a positive effect on the expected NPV of the investment, but Case 3 still has a risk of loss. The economic NPV had a $21 \%$ probability of loss, while it was $50 \%$ in the second case. The financial NPV likelihood of loss decreased from $41 \%$ to $15 \%$. Increasing the product selling price increased probability of having a positive NPV and increased the expected return.

While in Case 2 the economic NPV was greater than the financial NPV, in Case 3 the expected financial NPV of $\$ 81$ million was lower than the expected economic NPV of $\$ 84$ million. The higher fuel selling price results in higher profits from project investment. The negative cost of taxes had a larger impact than the benefit gained from the spread between debt and discount rate in the financing of capital debt. The NPV of taxes for case two was $\$ 18$ million, but in Case 3 the NPV of taxes was $\$ 39$ million.

At the same time, the financial IRR of $14 \%$ was slightly better than the economic IRR of $13 \%$. This is because of the initial capital investment being financed through debt. The financial case had a lower initial equity investment. The IRR had a minimum return of $-2 \%$ in this case, but the middle $80 \%$ of results were between $9 \%$ and $19 \%$. The expected IRR increased by $3 \%$ from the second to the third case.

Cases 1 to 3 have shown a range of possibilities. The following cases will isolate the effect of changes in either the product selling price or the initial capital investment.

3.4. Forward Contract: Fixed Selling Price. Case 4 is the same as Case 2 except for the selling price of fuel. While Case 2 had a variable selling price, this case has a fixed fuel price. The fuel price in this scenario is set to $\$ 2.68$ ( $\$ 0.71$ per liter) in real terms. This scenario isolates the uncertainty in return on investment caused by the technical variables. Table 11 shows the results.

The economic NPV is made to be zero by finding the break-even fuel price, while expected economic NPV did not change from Case 2. The expected economic NPV was equal to zero in both the second and the fourth scenarios, so although standard deviation decreased, half of the outcomes were positive and half were negative. Standard deviation decreased dramatically, from $\$ 101$ million to $\$ 21$ million. The probability of loss did not decrease.

The total range between the maximum and minimum financial NPV decreased from \$634 million to \$117 million from Case 2 to Case 4 . One standard deviation decreased from $\$ 76$ million to $\$ 15$ million. The probability of a loss in NPV decreased from $41 \%$ to $13 \%$. When risk is reduced to technical parameters, there is much less risk to the private investor. 
TABLe 10: Case 3 results.

\begin{tabular}{|c|c|c|c|c|c|c|}
\hline & \multicolumn{3}{|c|}{ Economic } & \multicolumn{3}{|c|}{ Financial } \\
\hline & NPV & IRR (nominal) & $B / C$ & NPV & IRR (nominal) & $B / C$ \\
\hline Expected value & $\$ 84,252,474$ & $12.6 \%$ & 1.24 & $\$ 80,672,958$ & $14.2 \%$ & 1.42 \\
\hline Standard deviation & $\$ 100,675,911$ & $3.1 \%$ & 0.29 & $\$ 76,305,318$ & $3.8 \%$ & 0.40 \\
\hline Max & $\$ 447,048,535$ & $22.7 \%$ & 2.30 & $\$ 349,991,319$ & $26.4 \%$ & 2.81 \\
\hline Min & $(\$ 268,437,824)$ & $-5.0 \%$ & 0.22 & $(\$ 190,303,825)$ & $-8.1 \%$ & 0.01 \\
\hline Probability of loss & $20.7 \%$ & & & $14.5 \%$ & & \\
\hline
\end{tabular}

TABLE 11: Case 4 results.

\begin{tabular}{|c|c|c|c|c|c|c|}
\hline & \multicolumn{3}{|c|}{ Economic } & \multicolumn{3}{|c|}{ Financial } \\
\hline & NPV & IRR (nominal) & $B / C$ & NPV & IRR (nominal) & $B / C$ \\
\hline Expected value & $\$ 0$ & $10.0 \%$ & 1.00 & $\$ 16,641,078$ & $11.0 \%$ & 1.09 \\
\hline Standard deviation & $\$ 20,684,124$ & $0.7 \%$ & 0.06 & $\$ 15,051,080$ & $0.9 \%$ & 0.08 \\
\hline Max & $\$ 79,292,123$ & $12.9 \%$ & 1.23 & $\$ 73,091,401$ & $14.5 \%$ & 1.38 \\
\hline Min & $(\$ 86,537,333)$ & $6.8 \%$ & 0.75 & $(\$ 43,554,644)$ & $7.3 \%$ & 0.77 \\
\hline Probability of loss & $50.2 \%$ & & & $13.2 \%$ & & \\
\hline
\end{tabular}

If the government were to guarantee biofuel producers a minimum or a fixed price for their product, private investors would become more interested in this industry. Under these circumstances, it is apparent that reducing fuel price uncertainty would encourage investment.

3.5. Forward Contract: Increasing Selling Price. Case 5 is similar to Case 4 in that the fuel price is fixed while the technical parameters are still forecast with uncertainty. The fuel price in Case 5 is fixed to meet the financial NPV in Case 3. Fuel price is fixed to $\$ 2.92$ ( $\$ 0.77$ per liter) in this case. It makes intuitive sense that the fixed fuel price is much higher in this scenario than in Cases 2 and 4 because of the higher product selling price. The results from this simulation are in Table 12.

Eliminating the fuel price uncertainty reduced the standard deviation in the financial NPV from \$76 million to $\$ 16$ million. The total range of financial NPVs decreased from $\$ 540$ million in case three to $\$ 114$ million in this case.

As in Case 3, the higher tax payments related to the higher fuel price result in a lower financial NPV than economic NPV. The financial IRR was better than the economic IRR because the financial IRR had a smaller initial investment cost.

Similar to our conclusion from Case 4 , we can say that fuel price uncertainty comprised a large part of the uncertainty in these experiments. The government could employ reverse auctions to reduce private risk and encourage investment in this infant industry.

3.6. Stochastic with Higher Capital Cost. For Case 6, we test the impact of higher-than-expected capital costs. Capital costs with new technologies and unknown production costs are difficult to predict. There has been a history of cost overruns for new technologies. Also, much of the literature casts the estimated capital cost as being for the $n$th plant. We attempted to measure the impact on project investment with a $20 \%$ cost overrun.
Case 6 uses the scenario in Case 3 as its base. Total capital investment is modeled as deterministic in all cases. Total capital investment increased by $20 \%$ in this case, from $\$ 429$ million to $\$ 514.8$ million. Table 13 summarizes the results.

With an $\$ 86$ million increase in upfront capital costs, the economic NPV changed by nearly the same amount, as would be expected. It was not exactly the same due to inflation. The financial NPV changed by about $\$ 60$ million. This occurs because the increased capital investment was decreased by adding taxes and financing. Probability of a loss was more than twice as high as in Case 3. Financial NPV probability of loss increased from $15 \%$ to $34 \%$ with only the change in capital costs.

The standard deviation, middle $80 \%$ range, and total range remained about the same, because the shift occurred to a deterministic parameter. The economic NPV distribution is remarkably similar to Case 2, because the NPV loss from increased capital cost was about equal to the NPV of the benefit accrued from the higher selling price.

3.7. Stochastic with Forward Contract. Case 7 is a model of the impact of a realistic reverse auction outcome. We start with the assumptions used in Case 3. Then, we add a forward contract for 45 MGY for project years 5-23 at the fixed fuel price used in Case 5.

Project years 5-23 were chosen because this is the time period in which the facility is producing at full capacity. In project year four, the facility is starting up, so it has a $75 \%$ start-up production rate.

To determine the forward contract volume, we measured the minimum fuel output based on the input uncertainty during the project timeline. We assume that the biofuel producer is willing to contract for the minimum expected facility fuel output. The minimum facility fuel output is above 45 million gallons (170 million liters) per year. The expected volume is 57.5 MGY but changes each year. The remaining volume beyond $45 \mathrm{MGY}$ is sold at the fuel price. 
TABLE 12: Case 5 results.

\begin{tabular}{|c|c|c|c|c|c|c|}
\hline & \multicolumn{3}{|c|}{ Economic } & \multicolumn{3}{|c|}{ Financial } \\
\hline & NPV & IRR (nominal) & $B / C$ & NPV & IRR (nominal) & $B / C$ \\
\hline Expected value & $\$ 84,252,474$ & $12.9 \%$ & 1.24 & $\$ 80,672,958$ & $14.7 \%$ & 1.42 \\
\hline Standard deviation & $\$ 21,955,577$ & $0.8 \%$ & 0.06 & $\$ 15,980,391$ & $1.0 \%$ & 0.08 \\
\hline Max & $\$ 157,793,602$ & $15.5 \%$ & 1.46 & $\$ 133,789,946$ & $17.8 \%$ & 1.69 \\
\hline Min & $\$ 3,099,769$ & $10.1 \%$ & 1.01 & $\$ 19,716,164$ & $11.1 \%$ & 1.10 \\
\hline Probability of loss & $0.0 \%$ & & & $0.0 \%$ & & \\
\hline
\end{tabular}

TABLE 13: Case 6.

\begin{tabular}{|c|c|c|c|c|c|c|}
\hline & \multicolumn{3}{|c|}{ Economic } & \multicolumn{3}{|c|}{ Financial } \\
\hline & NPV & IRR (nominal) & $B / C$ & NPV & IRR (nominal) & $B / C$ \\
\hline Expected value & $\$ 16,619,218$ & $10.5 \%$ & 1.04 & $\$ 32,599,899$ & $11.5 \%$ & 1.14 \\
\hline Standard deviation & $\$ 101,765,400$ & $2.9 \%$ & 0.25 & $\$ 77,252,890$ & $3.5 \%$ & 0.33 \\
\hline Max & $\$ 377,296,296$ & $18.7 \%$ & 1.91 & $\$ 311,273,718$ & $22.2 \%$ & 2.34 \\
\hline Min & $(\$ 341,382,691)$ & $-8.9 \%$ & 0.17 & $(\$ 238,976,396)$ & $-11.8 \%$ & -0.03 \\
\hline Probability of loss & $43.7 \%$ & & & $34.0 \%$ & & \\
\hline
\end{tabular}

The forecasted fuel price is nondeterministic and is the same as in Case 3.

The forward contract price used is $\$ 2.92$ (\$0.77 per liter). This is the price determined in Case 5 to provide the same expected return as in Case 3. $\$ 2.92$ per gallon ( $\$ 0.77$ per liter) could be the estimated average price over the 20year production period. The government benefits when the forward contract fuel price is below market fuel price. In other words, when the market fuel price is high, the government gains from a lower purchase price than what it could get on the open market. The opposite is also true. When the market fuel price falls below the contracted price, the government cannot choose to break the contract. It must purchase 45 MGY regardless of the market fuel price.

The total cost to government over the project timeline is expressed in NPV terms. Government cost is just the difference between the reverse auction contract price and the market price. The mean expected NPV is near zero because of the value of the forward contract fuel price. However, the variance of this cost is high. Case 7 shifts risk from the private sector to the public sector. The mean government cost is $-\$ 4.8$ million and one standard deviation is $\$ 74$ million. The government cost of the reverse auction could effectively range from $-\$ 260$ million to $\$ 250$ million.

Table 14 presents the results of this case. The expected NPV of this case is slightly lower than in Case 3, yet the variance is much lower. This is a result of the forward contract. In the first year-the startup year-of production, Case 3 had a fuel selling price of $\$ 2.92$ (\$0.77 per liter). The contract in Case 7 does not begin until the second year of production. The market price in the first year is on average much below this price so the benefit gained in the first production year of Case 3 is greater than in Case 7. The financial NPV probability of loss was reduced from $15 \%$ to $0 \%$. The economic NPV probability of loss decreased from $21 \%$ to $1 \%$.
This case quantifies how risk is transferred from the private to the public sectors through a reverse auction. Private investment in a biofuel production facility becomes much more appealing by having a forward contract. However, reverse auction is not commonly used in the United States. Much more common are tax breaks, low interest loans, or other capital subsidies.

3.8. Stochastic with Capital Subsidy. The government more often subsidizes the initial capital investment than it provides a forward contract. Case 8 uses the same expected public cost as in Case 7. However, while Case 7 had an uncertain public cost, the public cost in Case 8 is entirely deterministic: total capital investment is reduced in this case by $\$ 5$ million. Therefore, Cases 7 and 8 have the same expected government cost. Table 15 summarizes the results of Case 8 .

Although both cases have the same expected government cost, Case 8 has a specified cost while the government cost in Case 7 is uncertain. Case 8 has a slightly higher expected value than in Case 3 because of the lower capital cost. Still, the probability of loss is much higher than in Case 7: the probability of loss is $19 \%$ and $14 \%$ for the economic and financial cases, respectively.

\section{Conclusions}

The results reveal that product selling price uncertainty contributes greatly to the inherent risk of private investment in a biofuel production facility.

4.1. Cases 2 and 4. Cases 2 and 4 have the same expected economic NPV. Case 2 includes fuel price uncertainty, while Case 4 does not. Based on our estimates, it appears that private investment in biofuel production facilities could provide an expected $11 \%$ annual rate of return at a fuel 
TABle 14: Case 7.

\begin{tabular}{|c|c|c|c|c|c|c|}
\hline & \multicolumn{3}{|c|}{ Economic } & \multicolumn{3}{|c|}{ Financial } \\
\hline & NPV & IRR (nominal) & $B / C$ & NPV & IRR (nominal) & $B / C$ \\
\hline Expected value & $\$ 79,408,633$ & $12.7 \%$ & 1.23 & $\$ 76,991,639$ & $14.3 \%$ & 1.40 \\
\hline Standard deviation & $\$ 33,119,073$ & $1.1 \%$ & 0.10 & $\$ 24,732,466$ & $1.4 \%$ & 0.13 \\
\hline Max & $\$ 203,027,071$ & $16.7 \%$ & 1.59 & $\$ 171,025,408$ & $19.3 \%$ & 1.89 \\
\hline Min & $(\$ 28,653,844)$ & $9.0 \%$ & 0.92 & $(\$ 4,140,055)$ & $9.8 \%$ & 0.98 \\
\hline Probability of loss & $0.73 \%$ & & & $0.04 \%$ & & \\
\hline
\end{tabular}

TABle 15: Case 8.

\begin{tabular}{|c|c|c|c|c|c|c|}
\hline & \multicolumn{3}{|c|}{ Economic } & \multicolumn{3}{|c|}{ Financial } \\
\hline & NPV & IRR (nominal) & $B / C$ & NPV & IRR (nominal) & $B / C$ \\
\hline Expected value & $\$ 88,193,806$ & $12.8 \%$ & 1.26 & $\$ 83,474,418$ & $14.3 \%$ & 1.44 \\
\hline Standard deviation & $\$ 101,965,463$ & $3.2 \%$ & 0.30 & $\$ 77,349,466$ & $3.9 \%$ & 0.41 \\
\hline Max & $\$ 439,114,508$ & $22.1 \%$ & 2.29 & $\$ 351,062,589$ & $26.0 \%$ & 2.84 \\
\hline Min & $(\$ 269,840,864)$ & $-5.9 \%$ & 0.21 & $(\$ 191,571,723)$ & $-11.1 \%$ & 0.00 \\
\hline Probability of loss & $19.3 \%$ & & & $14.3 \%$ & & \\
\hline
\end{tabular}

TABLE 16: Cases 2 and 4 comparison.

\begin{tabular}{lcc}
\hline Financial measure & Case 2 & Case 4 \\
\hline Expected NPV & $\$ 16,641,078$ & $\$ 16,641,078$ \\
Standard deviation of NPV & $\$ 76,669,403$ & $\$ 15,051,080$ \\
Probability of loss & $40.8 \%$ & $13.2 \%$ \\
Total range & $\$ 634,209,848$ & $\$ 116,646,045$ \\
\hline
\end{tabular}

price of $\$ 2.68$ ( $\$ 0.71$ per liter), but including market price uncertainty makes this return rate highly uncertain. Case 2 had a $41 \%$ probability of loss even with an $11 \%$ expected IRR. The financial NPV ranged by $\$ 634$ million. Table 16 compares these two scenarios.

4.2. Cases 3 and 5. Case 3 had both technical uncertainty and a fuel price that followed DOE projections. Case 5 had technical uncertainty but not fuel price uncertainty. Fuel selling price in Case 5 was fixed to $\$ 2.92$ ( $\$ 0.77$ per liter), which provides the same expected NPV as in Case 3. The results of these two scenarios are compared in Table 17. Probability of a loss is greatly reduced from Case 3 to Case 5. Comparing the scenarios reveals the impact of fuel price uncertainty.

4.3. Cases 7 and 8. Case 7 forecasted the impact of a government originated reverse auction on profitability in investment. It had a forward contract for $45 \mathrm{MGY}$ of fuel at a price of $\$ 2.92$ ( $\$ 0.77$ per liter). The remaining facility fuel output was sold at wholesale gasoline and diesel prices. Under these conditions, the expected government cost was $\$ 4.8$ million, with a standard deviation of \$74 million.

Case 8 had a capital subsidy of $\$ 5$ million, slightly higher than the expected government cost in Case 7. Cases 7 and 8 are compared in Table 18.
TABLE 17: Cases 3 and 5 comparison.

\begin{tabular}{lcc}
\hline Financial measure & Case 3 & Case 5 \\
\hline Expected NPV & $\$ 80,672,958$ & $\$ 80,672,958$ \\
Standard deviation of NPV & $\$ 76,305,318$ & $\$ 15,980,391$ \\
Probability of loss & $14.5 \%$ & $0.0 \%$ \\
Total range & $\$ 540,295,144$ & $\$ 114,073,782$ \\
\hline
\end{tabular}

TABLE 18: Cases 7 and 8 comparison.

\begin{tabular}{lcc}
\hline Financial measure & Case 7 & Case 8 \\
\hline Expected NPV & $\$ 76,991,639$ & $\$ 83,474,418$ \\
Standard deviation of NPV & $\$ 24,732,466$ & $\$ 77,349,466$ \\
Probability of loss & $0.04 \%$ & $14.33 \%$ \\
Total range & $\$ 175,165,462$ & $\$ 542,634,312$ \\
\hline
\end{tabular}

4.4. Policy Implications. Investment in a fast pyrolysis commercial biofuel facility carries a high amount of risk. Case 3 shows that, with a total capital investment of $\$ 429$ million, the NPV could range from $-\$ 190$ million to $\$ 350$ million. Uncertainty arises directly from new technology and from market prices. This investment uncertainty arises from technical uncertainty and fuel price selling price uncertainty.

In our study, fuel price uncertainty was shown to have a large effect on investment risk. The government has many options for stimulating growth in biofuel production. However, to encourage private investment in biofuel production at the lowest public cost, the government should first look for ways to reduce private risk. Conventional fuels dominate the marketplace, and their prices are a direct competitor for dropin biofuels. To reduce risk, the government may consider ways by which it can control fuel price fluctuations for biofuel producers. A reverse auction would provide a competitive long-term price and would shift risk from the private sector to the public sector. In our study, a reverse auction was shown 
to be more effective at encouraging private investment than capital subsidies for the same expected cost.

\section{Conflict of Interests}

The authors declare that there is no conflict of interests regarding the publication of this paper.

\section{References}

[1] A. McCrone, E. Usher, O. V. Sonntag-'Brien, U. Moslener, and C. Grüning, "Global Trends in Renewable Energy Investment," United Nations Environment Programme, 2013, http://www .unep.org/pdf/GTR-UNEP-FS-BNEF2.pdf.

[2] Energy Efficiency and Renewable Energy, FY 2014 Budget Rollout. U.S. Department of Energy, 2013, http://wwwl.eere .energy.gov/office_eere/pdfs/budget/fy2014_eere_congressional budget_request.pdf.

[3] Bioenergy Technologies Office, "Replacing the Whole Barrel To Reduce U.S. Dependence on Oil," U.S. Department of Energy, 2013, https://www1.eere.energy.gov/bioenergy/pdfs/ replacing_barrel_overview.pdf.

[4] U.S. Energy Information Administration, Annual Energy Outlook, 2013, http://www.eia.gov/aeo.

[5] Bioenergy Technologies Office, "US Billion-Ton Update: Biomass Supply for a Bioenergy and Bioproducts Industry," U.S. Department of Energy, http://wwwl.eere.energy.gov/bioenergy/ pdfs/billion_ton_update.pdf.

[6] R. Tristan Brown, R. Thilakaratne, R. C. Brown, and G. Hu, "Techno-economic analysis of biomass to transportation fuels and electricity via fast pyrolysis and hydroprocessing," Fuel, vol. 106, pp. 463-469, 2013.

[7] S. B. Jones, C. Valkenburg, C. W. Walton et al., "Production of gasoline and diesel from biomass via fast pyrolysis, hydrotreating and hydrocracking: a design case," Pacific Northwest National Laboratory, http://www.pnl.gov/main/publications/external/technical_reports/PNNL-18284revl.pdf.

[8] R. P. Anex, A. Aden, F. K. Kazi et al., "Techno-economic comparison of biomass-to-transportation fuels via pyrolysis, gasification, and biochemical pathways," Fuel, vol. 89, no. 1, supplement, pp. S29-S35, 2010.

[9] S. B. Jones and J. L. Male, "Production of Gasoline and Diesel from Biomass via Fast Pyrolysis, Hydrotreating and Hydrocracking: 2011 State of Technology and Projections to 2017," Pacific Northwest National Laboratory, http://www .pnnl.gov/main/publications/external/technical_reports/PNNL22133.pdf.

[10] A. V. Bridgwater, "Review of fast pyrolysis of biomass and product upgrading," Biomass and Bioenergy, vol. 38, pp. 68-94, 2012.

[11] T. Bridgwater, "Biomass for energy," Journal of the Science of Food and Agriculture, vol. 86, no. 12, pp. 1755-1768, 2006.

[12] S. Czernik and A. V. Bridgwater, "Overview of applications of biomass fast pyrolysis oil," Energy and Fuels, vol. 18, no. 2, pp. 590-598, 2004.

[13] D. Mohan, C. U. Pittman Jr., and P. H. Steele, "Pyrolysis of wood/biomass for bio-oil: a critical review," Energy and Fuels, vol. 20, no. 3, pp. 848-889, 2006.
[14] M. M. Wright, D. E. Daugaard, J. A. Satrio, and R. C. Brown, "Techno-economic analysis of biomass fast pyrolysis to transportation fuels," Fuel, vol. 89, no. 1, supplement, pp. S2-S10, 2010.

[15] R. Tristan Brown and R. C. Brown, "Techno-economics of advanced biofuels pathways," RSC Advances, vol. 3, no. 17, pp. 5758-5764, 2013.

[16] T. Brown and G. Hu, "Technoeconomic sensitivity of biobased hydrocarbon production via fast pyrolysis to government incentive programs," Journal of Energy Engineering, vol. 138, no. 2, pp. 54-62, 2011.

[17] D. Meier, B. van de Beld, A. V. Bridgwaterorg et al., "State-ofthe-art of fast pyrolysis in IEA bioenergy member countries," Renewable and Sustainable Energy Reviews, vol. 20, pp. 619-641, 2013.

[18] C. E. Ridley, C. M. Clark, S. D. Leduc et al., "Biofuels: network analysis of the literature reveals key environmental and economic unknowns," Environmental Science and Technology, vol. 46, no. 3, pp. 1309-1315, 2012.

[19] W. E. Tyner, "Biofuels and agriculture: a past perspective and uncertain future," International Journal of Sustainable Development \& World Ecology, vol. 19, no. 5, pp. 389-394, 2012.

[20] D. Rajagopal and D. Zilberman, "Review of Environmental, Economic and Policy Aspects of Biofuels," Working Paper 4341, World Bank Policy Research, 2007.

[21] National Research Council, Renewable Fuel Standard: Potential Economic and Environmental Effects of US Biofuel Policy, National Academies Press, 2011.

[22] T. L. Richard, "Challenges in scaling up biofuels infrastructure," Science, vol. 329, no. 5993, pp. 793-796, 2010.

[23] L. J. Snowden-Swan and J. L. Male, "Summary of Fast Pyrolysis and Upgrading GHG Analyses," Pacific Northwest National Laboratory, 2012, http://www.pnnl.gov/main/publications/external/technical_reports/PNNL-22175.pdf.

[24] T. Searchinger, R. Heimlich, R. A. Houghton et al., "Use of U.S. croplands for biofuels increases greenhouse gases through emissions from land-use change," Science, vol. 319, no. 5867, pp. 1238-1240, 2008.

[25] W. E. Tyner, F. Taheripour, and D. Perkis, "Comparison of fixed versus variable biofuels incentives," Energy Policy, vol. 38, no. 10, pp. 5530-5540, 2010.

[26] W. Tyner, "Description of 2011 Biofuels Policy Alternatives," Policy Briefs 1, Global Policy Research Institute (GPRI), 2011.

[27] W. E. Tyner, "The US ethanol and biofuels boom: its origins, current status, and future prospects," BioScience, vol. 58, no. 7, pp. 646-653, 2008.

[28] KiOR, “Technology," 2013, http://www.kior.com/content/?s=11 \&t=Technology

[29] D. Humbird, R. Davis, L. Tao et al., "Process Design and Economics for Biochemical Conversion of Lignocellulosic Biomass to Ethanol: Dilute-Acid Pretreatment and Enzymatic Hydrolysis of Corn Stover," National Renewable Energy Laboratory, 2011, http://www.afdc.energy.gov/pdfs/47764.pdf.

[30] National Research Council, Transitions to Alternative Transportation Technologies: A Focus on Hydrogen, National Academies Press, 2008.

[31] J. R. Bartels, M. B. Pate, and N. K. Olson, "An economic survey of hydrogen production from conventional and alternative energy sources," International Journal of Hydrogen Energy, vol. 35, no. 16, pp. 8371-8384, 2010. 
[32] U.S. Government Accountability Office, "Corporate Income Tax: Effective Tax Rates Can Differ Significantly from the Statutory Rate," 2013, http://www.gao.gov/products/gao-13-520.

[33] Bureau of Labor Statistics, "Producer Price Index-Commodities," U.S. Department of Labor, 2013, http://www.bls.gov/ppi.

[34] S. Irwin and D. Good, "Farmdocdaily: What Combination of Corn and RINs Prices Makes E85 Competitive?" University of Illinois, http://farmdocdaily.illinois.edu/2013/06/ combination-corn-rins-prices-e85.html. 